\title{
Indicadores de desigualdade para financiamento urbano de cidades saudáveis
}

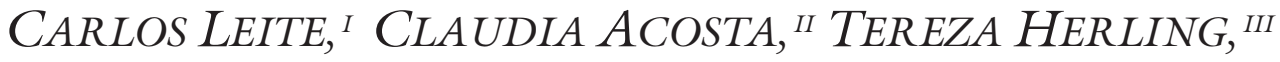 \\ LIGIA BARROZO IV e PAULO SALDIVA ${ }^{V}$
}

\section{Introdução}

A PESQUISA aborda as condições de vulnerabilidades social e em saúde e a segregação residencial no município de São Paulo, e o potencial uso de medidas científicas para instrumentos de financiamento urbano enquanto política pública promotora de inclusão socioterritorial.

Para tanto, as análises desenvolvidas procuram investigar quatro problemas complementares, com enfoques inter e multidisciplinares, a saber:

a) As condições de saúde se vinculam à segregação residencial no município de São Paulo? Quais as evidências que vinculam as condições de saúde e vulnerabilidade socioespacial no território?;

b) As condições de segregação residencial e desigualdades socioespaciais: quais as principais evidências e mapeamento territorial dos principais indicadores?;

c) Os instrumentos de financiamento urbano e promoção de inclusão socioespacial: quais os instrumentos existentes no marco regulatório urbano com maior potencial de utilização no financiamento da mitigação das desigualdades sociais e em saúde no uso do território urbano?

d) Os instrumentos de financiamento urbano identificados como promotores da mitigação das desigualdades se utilizam de evidências empíricas, indicadores baseados em pesquisa científica?

O uso mais inclusivo do território nas suas diversas e complexas dimensões em uma cidade com mais de 12 milhões de habitantes em 2018 e mais de $1.500 \mathrm{~km}^{2}$ de extensão é desafio importante para as diversas políticas públicas no ensejo de se promover uma cidade mais saudável e sustentável e que construa o desejável processo gradativo de alinhamento às premissas da Nova Agenda Urbana, reforçada pela Declaração das Cidades 2030 (UN Habitat, 2018) e de diversos Objetivos de Desenvolvimento Sustentável (ONU, 2015).

Os temas ora investigados se colocam na busca destas agendas e operam nas interfaces de diversos campos disciplinares - saúde pública urbana; vulnera- 
bilidade socioespacial, segregação residencial e geografia física; desenvolvimento urbano inclusivo, habitação social e urbanismo social; política fundiária e instrumentos de financiamento urbano ("land policy" e "land base tools"); sustentabilidade e ecologia urbanas. Diversas pesquisas se têm desenvolvido internacionalmente e, mais recentemente no Brasil e na cidade de São Paulo no que se refere a algumas dessas problemáticas e suas interfaces, sem a pretensão de esgotar as referências, apontamos por exemplo as recentes publicações de Fajersztajn et al. (2016), Barrozo et al. (2015), Marques (2015), Villaça (2011) e Leite et al. (2019).

Porém, além dos necessários avanços na construção das evidências empíricas mapeadas espacialmente, procurou-se nesta pesquisa avançar para uma fronteira ainda não investigada: a questão da possibilidade do financiamento das mitigações das vulnerabilidades sociais e em saúde no uso do território através de medidas científicas. Para tanto, analisou-se o instrumento urbano da Outorga Onerosa do Direito de Construir (OODC): instrumento pertencente ao rol das políticas fundiárias de mobilização da valorização do solo que recebeu relevante incremento no Plano Diretor Estratégico (PDE) da cidade em 2014 e possui as condições de não tributação e função redistributiva, ou seja, deve financiar os territórios de maior vulnerabilidade social (Leite et al., 2018).

\section{Saúde e segregação residencial em São Paulo}

Diga-nos onde mora e lhe diremos como é a sua saúde... Tão forte é a relação entre lugar e saúde, que teríamos grandes chances de acertar. Como disse Melody Goodman, "seu código de endereçamento postal é um melhor preditor de sua saúde do que seu código genético" (Roeder, 2014). Tal relação ocorre quando o espaço urbano reverbera o gradiente social na saúde. No nível do indivíduo, quanto mais baixa a posição socioeconômica de uma pessoa, pior sua saúde (Marmot, 2017). Como, em geral, os grupos sociais ocupam os espaços de acordo com sua posição social em uma cidade, também os problemas de saúde associados aos determinantes sociais se localizam de forma agregada, em um nítido padrão socioespacial. Tal degrau entre os estratos sociais tem sido observado em diversas cidades e realidades intraurbanas como em Baltimore, Estados Unidos da América e em Glasgow e Londres, Reino Unido (Marmot, 2017). A expectativa de vida ao nascer chega a ter diferença de mais de 20 anos entre os bairros mais ricos e os mais pobres nessas cidades. Não ocorre de forma diversa nos grandes centros urbanos do Brasil. Tamanhas discrepâncias em saúde e longevidade constituem uma questão de direitos humanos e, portanto, requerem ação e políticas públicas consistentes para reduzí-las (Weiss; Eikemo, 2017).

Encontrar os mecanismos sociais que sustentam tais diferenças entre os estratos pode contribuir para potencializar as ações para a redução desse degrau. Grande esforço científico tem sido feito nesse sentido nas últimas décadas. Embora no nível mais proximal, fatores como idade, sexo, código genético, escolaridade e estilo de vida expliquem grande parte da saúde de um indivíduo, a inte- 
ração desses com fatores intermediários e distais não pode ser negligenciada. O contexto da vizinhança está associado à saúde, independentemente dos atributos no nível do indivíduo. A qualidade ambiental (presença ou ausência de poluição do ar, por exemplo), a disponibilidade e acessibilidade aos serviços de saúde, oferta de alimentos saudáveis e infraestrutura de recreação, o capital e suporte social (que podem influenciar no comportamento das pessoas) e a importância da privação relativa são efeitos do contexto do lugar (Flowerdew et. al., 2008).

A segregação residencial das cidades brasileiras é tema importante da geografia, da sociologia e entre pesquisadores da área de planejamento urbano, tendo sido abordada por uma literatura vasta e diversa que procura elucidar seus mecanismos (Caldeira, 1996; Carlos, 2003; Lencioni, 2008; Villaça, 201 1, entre outros). No entanto, tem sido ainda pouco medida em termos empíricos, embora tenha sido bastante explicada do ponto de vista teórico. Diversos estudos em saúde têm apontado a segregação residencial como mais explicativa como fator distal do que a renda ou outras variáveis socioeconômicas (Huynh et al., 2017; Krieger et al., 2018). Aqui, avaliamos a segregação residencial por raça/ cor, por renda e por renda e raça/cor de forma combinada a partir dos Índices de Concentração nos Extremos (ICE), desenvolvidos por Massey (1996), com a finalidade de uma análise empiricamente embasada para o estudo da relação da segregação residencial em São Paulo com a mortalidade infantil pós-neonatal, ${ }^{1}$ um indicador clássico de condição de saúde.

Como uma medida de polarização socioespacial, o ICE quantifica os extremos dos grupos privilegiados e com privação em uma métrica única e avalia a extensão da concentração da população em um ou outro grupo.

$$
I C E_{i}=\frac{\left(A_{i}-P_{i}\right)}{T_{i}}
$$

$A_{i}$ : número de pessoas categorizadas como pertencendo ao extremo mais privilegiado;

$P_{i}:$ número de pessoas categorizadas como pertencentes ao grupo menos privilegiado;

$T_{i}$ : total da população na área estudada.

Assim, o ICE varia de -1 a +1 . Quanto mais próximo de -1 ou de +1 , maior a polarização no extremo inferior ou superior. $\mathrm{O}$ valor 0 indica que a área não é dominada por concentrações nos extremos de nenhum dos dois grupos (Huynh et al., 2017).

Os microdados do Censo Demográfico de 2010 (IBGE, 2010) foram extraídos para os cálculos de sete diferentes medidas de ICE: ${ }^{2}$ (1) ICE para renda, (2) ICE para cor/raça preta, (3) ICE para cor/raça preta, parda ou indígena (PPI), (4) ICE para educação, (5) ICE para renda e cor/raça preta, (6) ICE para renda e cor/raça branca, (7) ICE para renda e cor/raça PPI. A unidade geográfica foi a área de ponderação do Censo Demográfico. 
O risco relativo de mortalidade infantil pós-neonatal correspondeu aos óbitos entre residentes do município de São Paulo ocorridos entre 2006 e 2009, por todas as causas, padronizados por sexo. O período de quatro anos foi definido para manter estabilidade da taxa, evitando flutuações aleatórias entre os anos.

A relação entre os riscos de mortalidade infantil pós-neonatal e os indicadores de segregação residencial foi avaliada por meio da aplicação de regressões (Mínimos Quadrados Ordinários, regressões espaciais globais e regressões geograficamente ponderadas. ${ }^{3}$

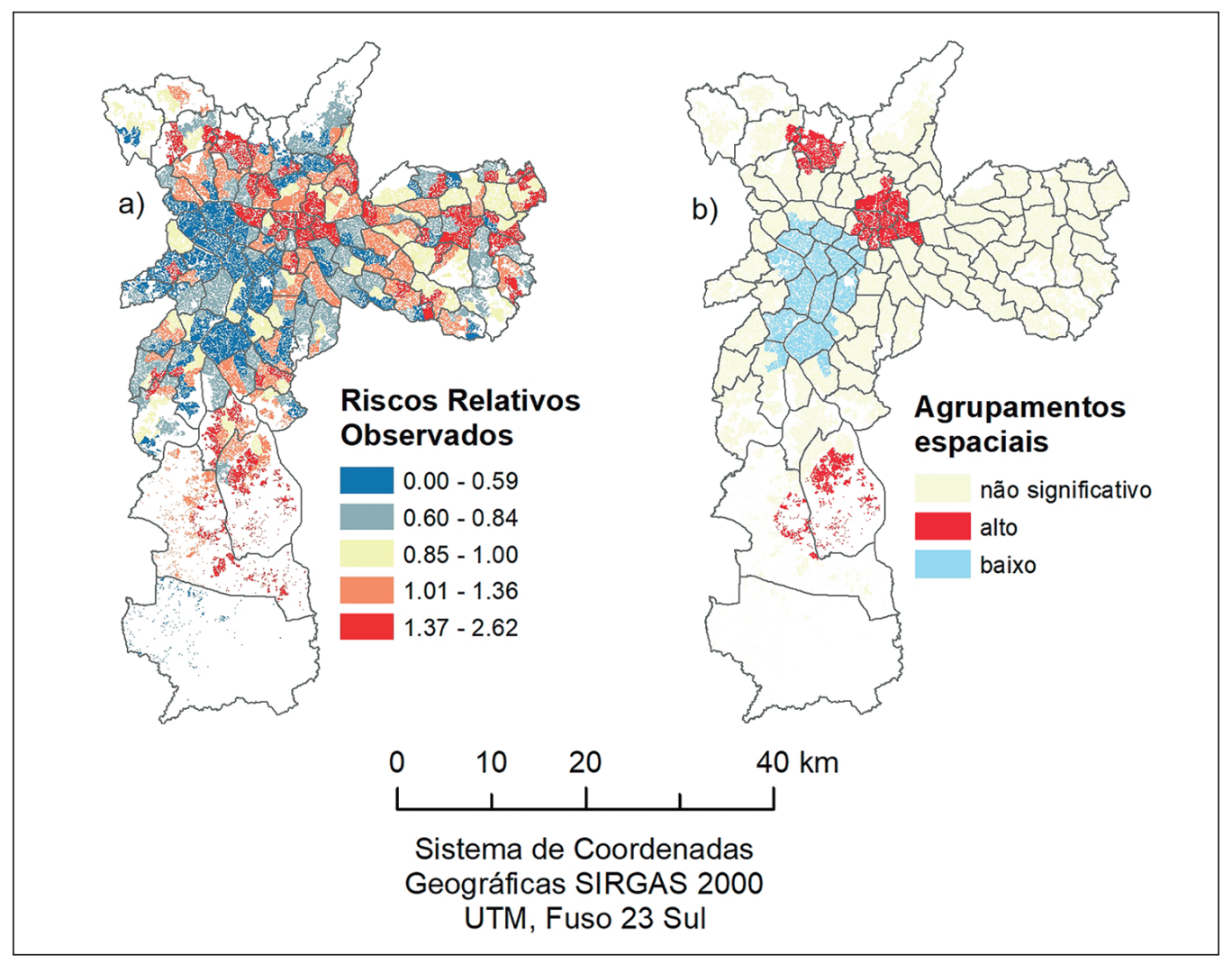

Fontes: Cartografia: IBGE (2010); Barrozo et al. (2015); Dados de mortalidade: Datasus; Dados de população: IBGE (2010).

Figura 1 - Distribuição espacial da mortalidade infantil pós-neonatal ocorrida entre residentes do Município de São Paulo, de 2006 a 2009: a) Riscos relativos; b) Agrupamentos espaciais.

A busca por evidências empíricas da relação entre saúde e segregação permite-nos afirmar que, apesar de o padrão espacial da mortalidade estudada apresentar fraca tendência a agrupamento considerando o município como um todo (Figura la), ocorreram agrupamentos locais significativos (Figura lb). Segundo Deaton (2003), a mortalidade infantil em países em desenvolvimento é primariamente uma consequência da pobreza; a renda baixa seria o fator importante e não a desigualdade de renda em si. O modelo aqui encontrado com base na 
segregação residencial por cor/raça explica de forma satisfatória os riscos relativos da porção central e norte do município, embora subestime os riscos na porção sul (Distritos Cidade Dutra, Grajaú e Parelheiros). Foi o melhor modelo entre todos os tipos de segregação aqui avaliados, salientando a questão racial e a questão racial combinada com a renda, no terceiro modelo mais explicativo. É importante ressaltar que essa segregação ocorre na área, já que se trata de um estudo ecológico, para o qual os dados são agregados. Assim, não necessariamente apenas crianças de raça/cor preta, parda ou indígena foram a óbito, mas a segregação por raça/cor do local de moradia é o indicador de maior associação para a mortalidade pós-neonatal em São Paulo. Quando os óbitos neonatais (bebês entre 0 e 27 dias completos) são incluídos na análise - a segregação residencial por raça/cor e renda combinadas explicam mais a mortalidade infantil do que a renda de forma isolada (Barrozo, 2018).

A relação observada entre saúde e segregação residencial tem sido maior do que a relação entre saúde e medidas de pobreza, para diversos desfechos nos Estados Unidos, em diversos níveis de agregação dos dados (Krieger et al., 2018). Os resultados aqui apresentados apontam para a importância da segregação residencial associada à cor/raça na mortalidade infantil pós-neonatal. Esse tópico necessita de uma melhor compreensão, já que análises ecológicas são limitadas para capturar os processos subjacentes. Apesar disso, tem-se compreendido a segregação residencial como um fator estrutural que ajuda a perpetuar a desigualdade social (Mackenbach, 2017). Algumas teorias contribuem para compreender as iniquidades na mortalidade estudada. Uma das explicações diz que as iniquidades em saúde fluem da distribuição sistematicamente desigual de poder político, prestígio e recursos entre os grupos da sociedade (Weiss; Eikemo, 2017). Um importante recurso é o acesso às informações. Segundo a teoria da difusão de inovações (Phelan et al., 2010), as mortalidades apresentam maior desigualdade entre os grupos sociais quando correspondem a causas evitáveis como a mortalidade infantil pós-neonatal porque os grupos dos estratos sociais mais altos têm acesso ao conhecimento e aos recursos necessários para a prevenção. Sem a pretensão de explicar a raiz da segregação residencial no Brasil e em São Paulo, os resultados desse estudo apenas apontam para a necessidade de se olhar mais cuidadosamente para a questão racial nas análises de desigualdade em saúde. Talvez sejam necessárias políticas públicas direcionadas a grupos específicos de pessoas mais vulneráveis entre os vulneráveis ou intervenções para a redução da segregação residencial.

A quinta causa básica mais importante de óbitos no período estudado compreendeu as mortes por diarreia e gastroenterite de origem infecciosa presumível (92 crianças). Além das condições de maior precariedade das moradias e de seus entornos (infraestrutura urbana e de suporte) e desvantagem nas condições de educação e renda, serviços de saúde de baixa qualidade em lugares onde há maior população de raça/cor preta ou PPI podem explicar como a segregação residencial estaria associada ao maior risco de mortalidade pós-neonatal. Outros estudos são necessários para verificação dessa hipótese. 


\section{Segregação residencial e desigualdades socioespaciais no município de São Paulo}

O conceito de segregação residencial pode ser compreendido como constituinte de processos de segregação socioespacial que conformam a estrutura intraurbana das cidades. Trata-se, em linhas gerais, do processo de concentração de determinada classe social em uma determinada porção do território - uma região ou um conjunto de bairros. Os autores Villaça (2011) e Castells (1979) identificam uma relação diretamente proporcional entre estratificação de renda e segregação socioespacial, ou seja, quanto mais estratificada uma sociedade (ou mais desigual em termos de renda), maior a tendência à concentração das classes mais altas em determinadas porções do território. Em São Paulo verifica-se que as camadas médias e alta da população concentram-se majoritariamente no setor sudoeste da cidade, ainda que haja presença dessas classes em porções menores e mais isoladas no município, como o Jardim São Paulo, a norte, ou a Chácara Santo Antônio, a sul ou ainda o Jardim Anália Franco e o Tatuapé a leste.

As regiões de concentração das camadas médias e alta da população são, também, aquelas cujos imóveis têm os preços mais altos da cidade, o que aponta uma relação direta entre segregação socioespacial e valorização imobiliária. $\mathrm{O}$ valor da terra seleciona, portanto, quem pode ter acesso às porções do território com urbanização mais consolidada, servida pelas redes de infraestrutura, transporte e equipamentos públicos de qualidade, num processo que amplia a desigualdade de renda com desigualdade de acesso à cidade bem estruturada. Porém, o valor da terra decorre, principalmente, dos investimentos públicos realizados em seu território - quanto mais investimentos em transporte, por exemplo, mais se eleva o preço da terra e mais restritiva se torna como local de moradia das camadas populares. Esse processo pode ser corrigido com políticas públicas, seja pelo reequilíbrio dos investimentos no território da cidade, especialmente nos bairros mais precários, seja pela utilização de instrumentos urbanísticos de redistribuição dos ganhos de valorização imobiliária, como se verá na próxima parte deste artigo.

Em São Paulo, o poder público acabou reforçando os processos de valorização imobiliária do setor sudoeste da cidade, principalmente através da concentração de investimentos públicos no sistema de transporte e no sistema viário, que garantem ganhos de tempo de deslocamento para seus moradores de forma bastante diferenciada do restante da cidade. Um amplo conjunto de indicadores pode nos apontar desigualdades socioespaciais entre territórios do setor sudoeste do município, situado entre os rios Pinheiros e Tietê, e os bairros periféricos. O primeiro é a valorização imobiliária, expressa no mapa através da arrecadação do Imposto Predial e Territorial Urbano (IPTU). Vale lembrar que há também uma forte concentração de propriedades imobiliárias no município de São Paulo, onde $1 \%$ dos proprietários é dono de $25 \%$ de todos os imóveis registrados no município, cujo valor também é alto, atingindo $45 \%$ do valor total de imóveis da cidade (cerca de R\$ 749 bilhões) (Burgarelli et al., 2016). 


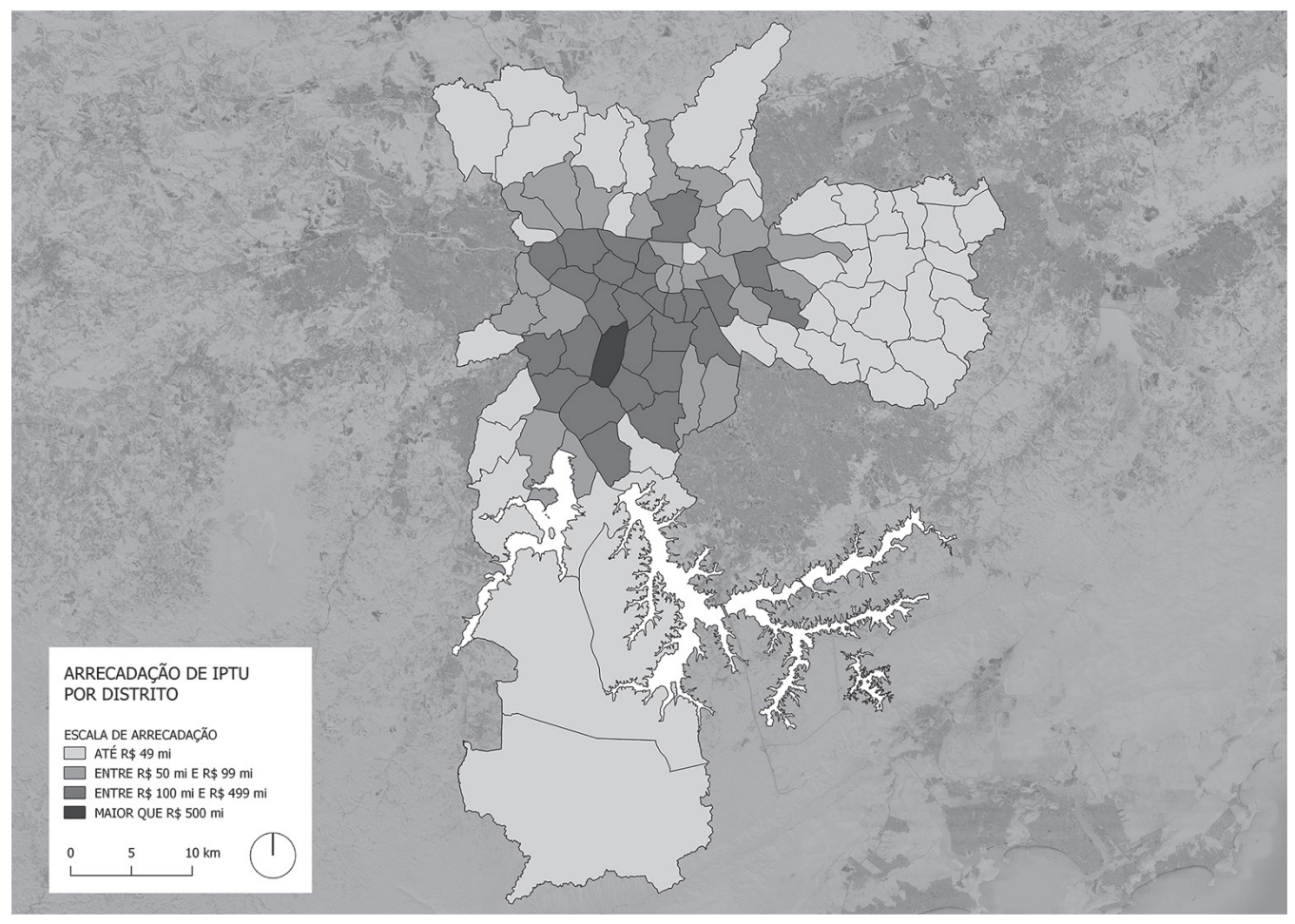

Fonte: Secretaria Municipal da Fazenda. Valores referentes à arrecadação por distrito foram coletados da base replicada em 27.8.2017; elaboração própria a partir do Mapa da Desigualdade (RNSP, 2018).

Figura 2 - Arrecadação de IPTU por distrito no município de São Paulo.

O setor sudoeste, por sua vez, concentra as melhores oportunidades urbanas, tanto com relação à oferta de empregos formais quanto com relação à rede de equipamentos e espaços públicos e à infraestrutura urbana, ao passo que as regiões periféricas são justamente aquelas por onde se espraiam os locais de moradia precária, coincidentes com os setores de mais alta vulnerabilidade social, conforme indica o Índice Paulista de Vulnerabilidade Social (IPVS).

O mapa da Figura 2 é, portanto, emblemático da distância entre locais de moradia da população pobre e locais com oportunidades de desenvolvimento social, seja pelo trabalho, seja pelo acesso a serviços públicos de qualidade. $\mathrm{O}$ transporte público se torna crucial, portanto, para viabilizar essas conexões.

Contudo, os investimentos públicos na estruturação do sistema de transporte público coletivo em São Paulo - redes de ônibus de média e alta capacidades e metrô - ainda não atingiram de forma mais equânime as distantes áreas da periferia, onde moram justamente as camadas mais pobres da população. Segundo pesquisa da Rede Nossa São Paulo, cerca de metade da população usa o ônibus como modo de transporte público preferencial, de uma a cinco vezes por semana, sendo que para as famílias com renda familiar média mensal entre dois e cinco salários mínimos, essa taxa é de 57\%. Porém, o tempo investido nos des- 


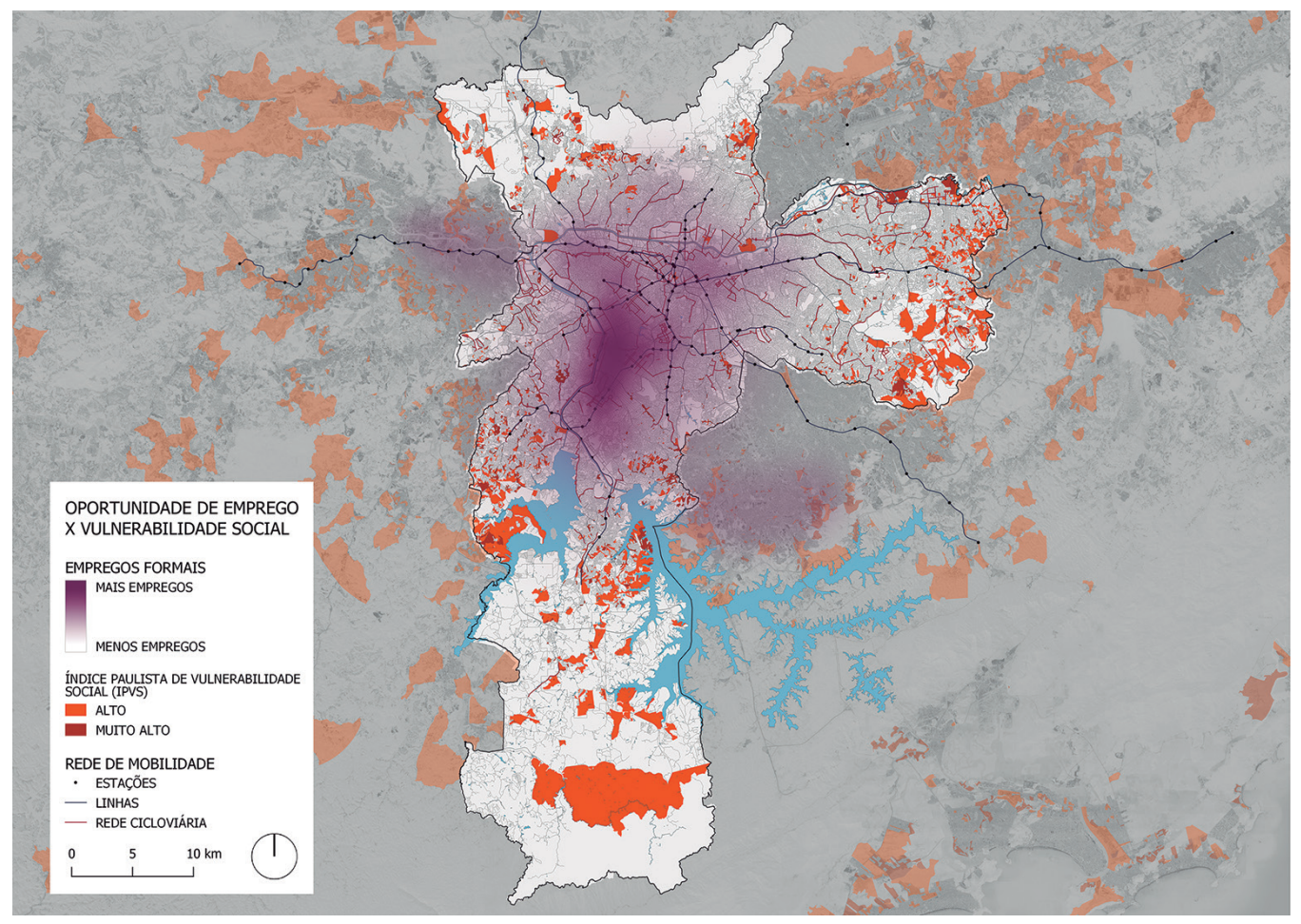

Fonte: Elaboração própria a partir de dados disponíveis na plataforma Geosampa (SMUL/ PMSP) - Disponível em: <www.geosampa.prefeitura.sp.gov.br>. Acesso em: 15 jan. 2019.

Figura 3 - Oportunidade de emprego X Vulnerabilidade Social X Transporte Público.

locamentos varia bastante, conforme a região de moradia dessas famílias, não só em razão de distâncias percorridas, mas em razão da desigualdade na cobertura da rede. Enquanto o tempo médio de deslocamento de moradores das regiões Norte e Sul da cidade gira em torno de 2h05minutos, o tempo médio de deslocamento dos moradores da região Oeste para suas atividades principais (trabalho ou estudo) gira em torno de 1 h33, uma diferença $25 \%$ do tempo a mais de deslocamento no transporte nas regiões menos favorecidas. Outro fator que agrava essa desigualdade é o impacto do preço das tarifas no orçamento familiar, o que impede mais da metade das famílias de realizar visitas ou atividades de lazer. Segundo a mesma pesquisa, as pessoas que mais são afetadas por essa restrição são as mulheres com Ensino Médio completo, que possuem renda familiar média mensal de até dois salários mínimos, da classe $\mathrm{C}$, pretas ou pardas, moradoras da zona Leste (RNSP, 2018). Saldiva (2018, p.75) aponta essa disfunção da vida urbana como um "pedágio urbano na imobilidade" ou "velocidade social" ou ainda "velocidade efetiva".

Se o acesso às áreas melhor infraestruturadas da cidade é dificultado pela rede desigual de transporte público, por outro lado, os locais de moradia das camadas mais pobres da população ainda são, em sua grande maioria, bastante precários. Sua urbanização foi feita, majoritariamente, por processos espontâne- 
os de ocupação de glebas periféricas, muitas delas irregulares, seja do ponto de vista urbanístico, seja do fundiário. Muitas dessas ocupações avançaram sobre áreas ambientalmente frágeis, o que explica a grande incidência das áreas de alto risco geológico de escorregamento em assentamentos precários. A população vivendo de forma precária no município atinge $26 \%$ do total de domicílios da cidade. Segundo informa o Plano Municipal de Habitação de São Paulo (SMH, 2016), a precariedade habitacional atingia cerca de 950 mil domicílios. Pelo mapa da Figura 3, nota-se que a grande maioria dos assentamentos precários se situa na região Sul, principalmente próximo aos mananciais de abastecimento de água das represas Guarapiranga e Billings. Note-se, coincidentemente com a conclusão das análises apresentadas na primeira parte relativas à saúde urbana, que o grau de precariedade das favelas não estava associado à renda de seus moradores, mas sim à sua localização no município, refletindo o grau de urbanização de seu entorno imediato.

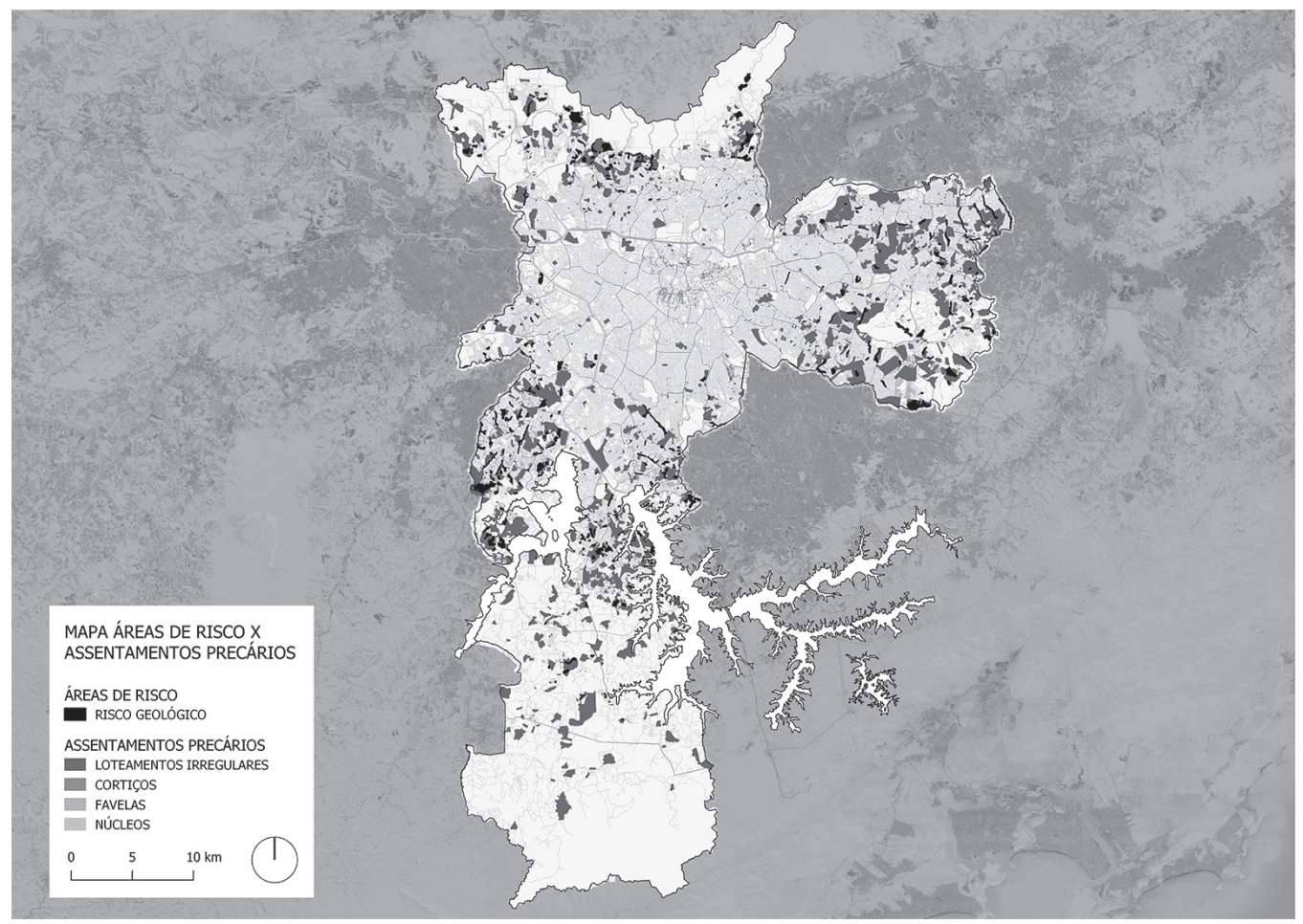

Fonte: Elaboração própria a partir de dados disponíveis na plataforma Geosampa (SMUL/ PMSP) - Disponível em: <www.geosampa.prefeitura.sp.gov.br>. Acesso em: 15 jan. 2019.

Figura 4 - Mapas de favelas, loteamentos irregulares e cortiços e as áreas de risco ambiental.

A condição de moradia é considerada precária não só por seus aspectos construtivos - insuficiência de iluminação ou ventilação, instalações elétricas com riscos à segurança, instabilidade das estruturas, por exemplo -, mas, principalmente, pelas condições da urbanização da região em que se inserem. Em 
geral, há quatro fatores essenciais que caracterizam essa precariedade, que afetam diretamente as condições de saúde da população e que demandam ação pública para sua solução: i) insuficiência no atendimento às redes de infraestrutura urbana; ii) existência de áreas de risco de escorregamento ou inundação; iii) deficiência nos processos de coleta de lixo; iv) ausência de espaços públicos adequados, principalmente para a circulação de pedestres, bicicletas e carros. Vale lembrar que, ainda que ocorra de forma mais intensa nas ocupações irregulares, principalmente nas favelas, essas condições de precariedade são comuns ao entorno dos assentamentos, nos chamados bairros regulares e afetam diretamente a saúde dos grupos populacionais mais vulneráveis - mulheres, crianças e idosos.

Entre 2013 e 2014, a então Secretaria Municipal de Desenvolvimento Urbano (SMDU) elaborou estudos no âmbito do processo de revisão do PDE para verificar a carência de equipamentos sociais essencialmente vinculados ao atendimento local - creches, escolas de ensino fundamental, unidades básicas de saúde - e identificar aquelas porções do território com maior carência de equipamentos. O mapa da Figura 4 evidencia mais um indicador da desigualdade entre os setores da cidade mais consolidados e suas periferias, com maior carência justamente nas áreas ocupadas por aquelas famílias mais vulneráveis do ponto de vista social e, em sua maioria, moradoras em assentamentos ou bairros precários. A ausência de creches é um fator que reforça a já alta vulnerabilidade social daquelas famílias chefiadas por mulheres sozinhas. Às dificuldades decorrentes de transporte público precário e caro a falta de creches reduz as possibilidades de essas mulheres saírem de casa para conseguir trabalho e renda, num círculo vicioso que impossibilita o desenvolvimento dessas famílias.

A precariedade de espaços públicos nos territórios periféricos impõe diversas barreiras ao seu pleno uso pelos moradores, seja pelas barreiras impostas à mobilidade de pedestres e ciclistas, seja pela insuficiência de áreas livres abertas - praças e parques - para uso de seus moradores. Sua sociabilidade conta muitas vezes com espaços improvisados. A rede cicloviária da cidade ainda se concentra no setor sudoeste da cidade. Além de precárias, as calçadas não recebem iluminação pública adequada, o que representa riscos para a circulação de mulheres jovens durante a noite.

Dos inúmeros indicadores que poderiam atestar as diferenças entre viver nos bairros periféricos e nos bairros do setor sudoeste, o mais dramático deles é o de expectativa de vida que, por sua vez, está relacionado com o homicídio juvenil. $\mathrm{O}$ desenho desse setor é facilmente identificado nas áreas mais claras do mapa à Figura 5, onde há o menor número de registros de mortes por homicídio por 100 mil habitantes na faixa etária entre 15 e 29 anos. A precariedade e a insuficiência de atendimento por serviços básicos, equipamentos sociais e outros indicadores de qualidade de vida no município para o atendimento às necessidades de crianças fora do período de aula, adolescentes e jovens se fazem sentir não como explicação absoluta, mas como indicador de possíveis causas para a diferença entre a mortalidade de jovens nas áreas centrais e na periferia. 


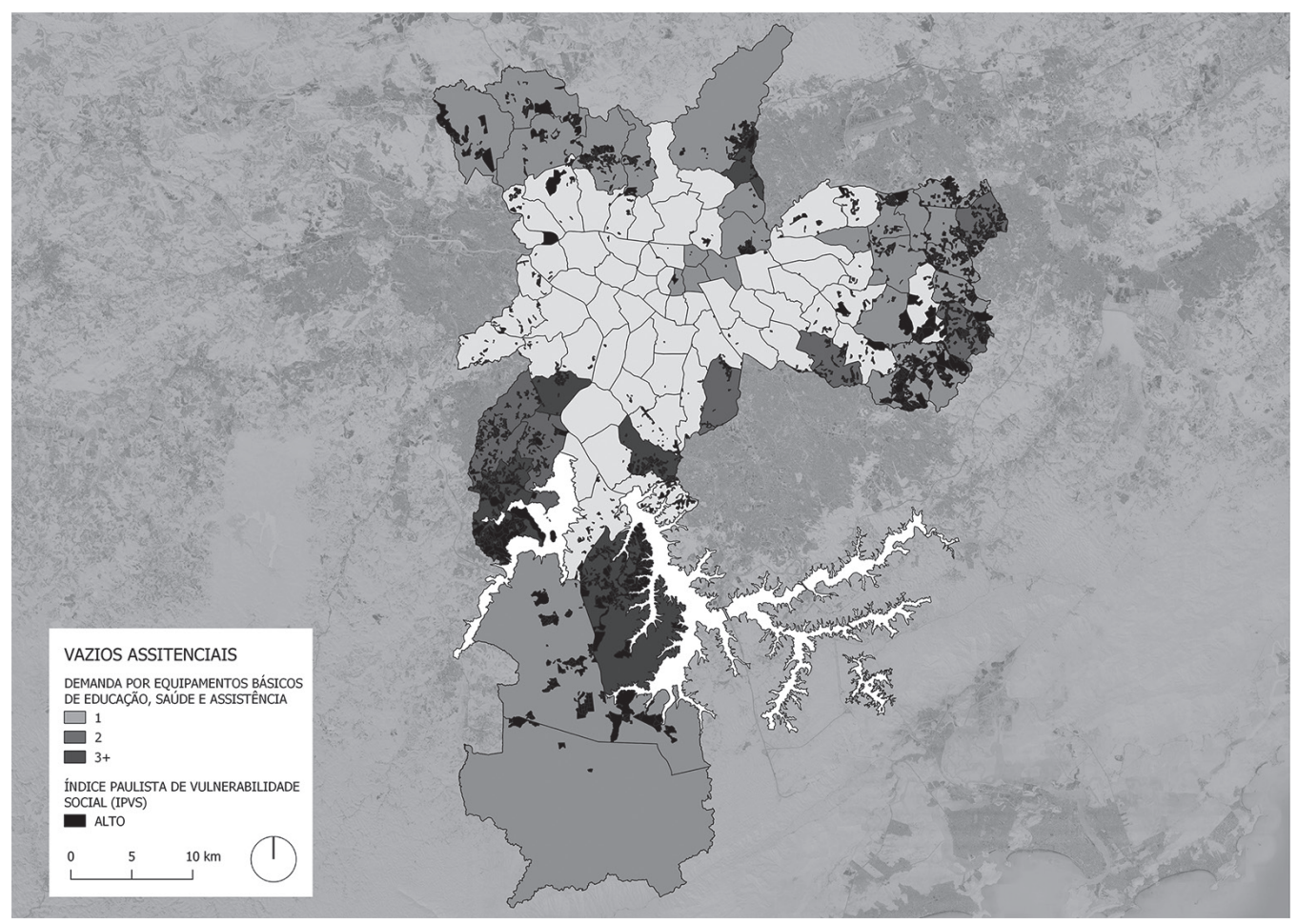

Fonte: Elaboração própria a partir de dados disponíveis na plataforma Geosampa (SMUL/ PMSP) - Disponível em: <www.geosampa.prefeitura.sp.gov.br>. Acesso em: 15 jan. 2019, e SMDU (2016).

Figura 5 - Vazios assistenciais e concentração demográfica com altos índices de vulnerabilidade social.

\section{Instrumentos de financiamento urbano e inclusão socioterritorial no município de São Paulo}

A configuração das cidades obedece a processos históricos muito profundos, diretamente vinculados ao funcionamento do mercado fundiário. Na América Latina, e São Paulo não é exceção, o mercado do solo urbano se caracteriza pela captação pelos agentes privados da valorização da terra derivados do esforço social e público, o que permite uma acumulação acelerada do capital. Também é comum a baixa capacidade do Estado, seja como regulador do mercado, seja como agente fiscal, de coerção e controle das ações privadas e na provisão de bens e serviços, incluindo a moradia social.

Como discutido anteriormente, em São Paulo os grupos mais ricos se concentram na região Sudoeste, que possui os melhores atributos urbanos, e, consequentemente, as melhores oportunidades urbanas. Enquanto isso, restam às camadas mais pobres as piores localizações, tanto no sentido físico individual, como no de atributos coletivos (redes, infraestruturas, espaços públicos). Ainda que a exclusão socioespacial não seja um fenômeno unicausal nem unidimensional, a organização dos grupos sociais na configuração urbana ocorre principal- 


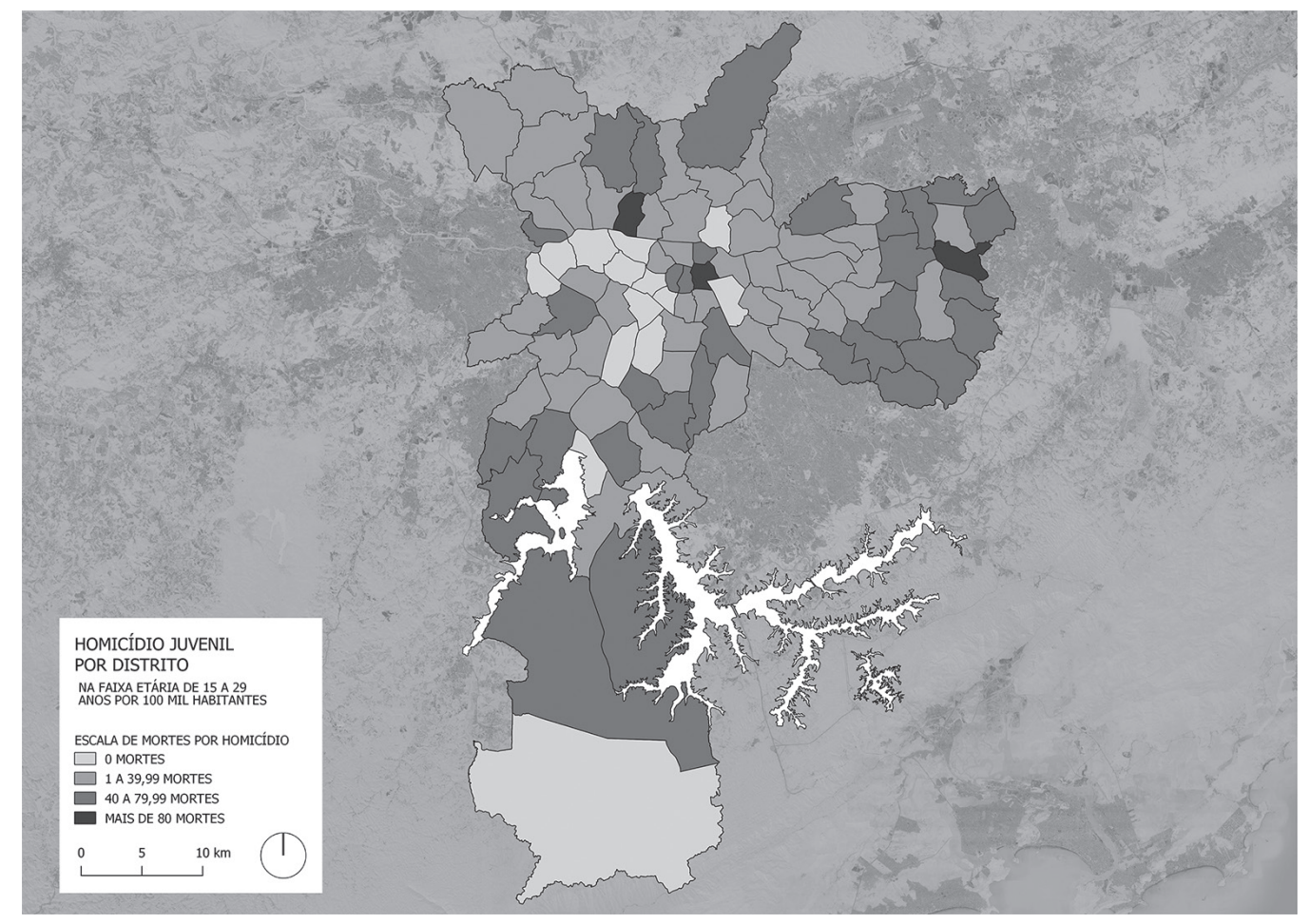

Fonte: Elaboração própria a partir de: SIM (Sistema de Informação sobre Mortalidade), Secretaria Municipal de Saúde; Programa de Aprimoramento das Informações de Mortalidade; CEInfo (Coordenação de Epidemiologia e Informação); IBGE, 2010; SMUL (Secretaria Municipal de Urbanismo e Licenciamento), Departamento de Produção e Análise de Informação/Deinfo. Ano 2015; Mapa da Desigualdade 2017 (RNSP, 2018).

Figura 6 - Homicídio Juvenil por distrito.

mente a partir de uma ferramenta de mercado: o preço da terra. Assim, quem consegue pagar mais ocupa as melhores localizações; aos demais são reservadas as categorias de localização menos qualificadas e valorizadas, seja no mercado formal ou informal.

A valorização dos imóveis no território da cidade decorre dos investimentos públicos acumulados historicamente, especialmente em infraestrutura de suporte - a infraestrutura básica (abastecimento de água, esgotamento sanitário, drenagem, coleta de lixo e energia) e as redes de transporte, de equipamentos e serviços e de espaços públicos - e essa valorizacão podem e devem ser capturadas e compartilhadas entre toda a sociedade que, afinal, financiou tais investimentos, pagando impostos (Smolka; Amborski, 2000).

Há diversos instrumentos legais disponíveis para a correção dos históricos desequilíbrios sócio-territoriais que podem ser utilizados para, inclusive, reduzir a distância entre os estratos sociais. A recuperação, a captura ou a mobilização da valorização fundiária (land value capture; land value sharing) se materializam em ações e instrumentos tributários e não tributários, regulatórios, obrigações, 
condicionamentos ao direito de propriedade, entre outros. Os instrumentos se orientam a retornar direta ou indiretamente à comunidade os recursos criados pelo esforço público a fim de reverter a desigualdade territorial e financiar a cidade (Furtado; Acosta, 2013).

Há um conjunto de instrumentos urbanos de política fundiária potencialmente promotores do chamado urbanismo social, previstos no PDE 2014, que podem ser aplicados para garantir um uso mais justo e equilibrado do território urbano, como a garantia de terras para produção de habitação de interesse social, como as Zonas Especiais de Interesse Social (ZEIS) (Nobre, 2016).

Mas o instrumento urbano da OODC é aquele que possui os melhores atributos para financiar as mitigações das vulnerabilidades social e em saúde no uso do território. A OODC é uma resposta de política pública urbana que $(i)$ regula o direito de construir em favor da coletividade; (ii) reduz o efeito econômico diferenciado derivado das decisões administrativas vinculadas à concessão de benefícios urbanísticos; e (iii) recupera parte da valorização acumulada historicamente decorrente de obras e infraestruturas já realizadas.

O montante arrecadado tem representado, nos anos de maior arrecadação, como em 2011, o equivalente a 11,5\% do volume total de investimentos municipais (Equino; Leite, 2018). A natureza extraorçamentária, o caráter não tributário e a finalidade redistributiva do instrumento abrem uma importante oportunidade para priorizar investimentos orientados a reduzir as diferenças por demandas socio-territoriais entre as regiões da cidade.

De que forma a OODC pode ser um instrumento para combater os enormes desequilíbrios territoriais da cidade? Os recursos da OODC são "carimbados" por disposição legal com um claro objetivo redistributivo, tendo seu uso possível em promoção de regularização fundiária, habitação de interesse social, reserva fundiária, ordenamento da expansão urbana, equipamentos urbanos e comunitários, de lazer e áreas verdes, proteção ambiental, cultural ou paisagística. Os recursos são capturados nos empreendimentos imobiliários lançados nas regiões mais valorizadas da cidade e são administrados pelo Fundo Municipal de Desenvolvimento Urbano (Fundurb), cujo conselho decide em que e onde direcionar os recursos, devendo ocorrer em ações e regiões de maior vulnerabilidade social. A partir do PDE 2014, ficou estabelecido que pelo menos 30\% dos recursos devam ser direcionados à obtenção de terra destinada a moradia social, e outros 30\% à questões relativas à mobilidade urbana (PDE, 2014: Parágrafo $2^{\circ}$, Artigo 340).

Evidentemente, essa vinculação não garante que os recursos serão utilizados de maneira redistributiva. Para saber se de fato ocorre redistribuição do recurso necessitamos analisar tanto a geração do recurso via OODC como as decisões de investimento desses recursos, via Fundurb.

Com um objetivo exploratório, nossa análise foca no período 2012-2017 para arrecadação de OODC, e 2013-2018 para as decisões de alocação espacial 
e montantes desses recursos pelo Fundurb. Para realizar o estudo detalhado da discriminação dos investimentos é preciso conhecer cada projeto e sua localização, dados que estão disponíveis só a partir de 2013.

A primeira evidência, que não surpreende, é que a arrecadação de recursos da OODC no município é concentrada ao redor das áreas centrais e no vetor centro-sudoeste. Esse comportamento responde, além da concentração de ren$\mathrm{da}$, às áreas para as quais a cidade liberou os maiores estoques para construção no PDE de 2012. Evidentemente a demanda por densidade se dá nas áreas de maior atração do capital imobiliário.

Durante os anos 2012, 2013 e 2014, a arrecadação se concentrou principalmente no eixo centro-sudoeste, com atividade na zona leste (Tatuapé e arredores). Mas, a partir de 2015, as regiões de Moema, Vila Mariana e Saúde ganham força, assim como a região Norte mais próxima do centro.

Durante esses anos, a arrecadação se manteve bastante constante, com valores ligeiramente superiores aos R 200 milhões, com exceção de 2017, ano em que cai consideravelmente aproximadamente para R 130 milhões. No total do período, a arrecadação foi de cerca de $\mathrm{R} \$ 1,3$ bilhão, dos quais $72 \%$ foram arrecadados dentro do centro expandido.

Para conferir o comportamento do investimento foram analisados os projetos financiados com recursos do Fundurb entre 2013 e 2018. Ainda que tenha havido mudanças entre o PDE de 2002 e o de 2014, essas se orientaram basicamente a detalhar a destinação. Foram investidos aproximadamente US\$ 430 milhões, com a seguinte distribuição:

Quando observamos a distribuição dos investimentos no espaço, notamos o quanto ela é ampla no município. Se durante 2013 e 2014 os recursos pareceram acompanhar projetos de estrutura urbana cruzando a cidade de leste a oeste, em 2016 deu-se prioridade ao vetor centro-sul.

$\mathrm{Na}$ Figura 7 se apresenta o comportamento territorial da arrecadação de OODC e de investimentos do Fundurb para o período analisado.

Quando dividimos a cidade entre centro expandido e os demais bairros da cidade, as áreas geradoras de arrecadação de recursos via OODC se concentram dentro do centro expandido, com especial destaque para Moema e Pinheiros. Por sua vez, os recursos de investimento realizados pelo Fundurb foram maioritariamente nas regiões periféricas: o extremo noroeste (Perus, Pirituba), leste e sudeste (Aricanduva-Formosa, Itaquera, Vila Prudente, com destaque para São Mateus), extremo oeste (Raposo Tavares), extremo sul de Ipiranga, e o centro histórico da cidade (Sé). ${ }^{4}$

A fim de comparar geração e recepção por área de ponderação, realizou-se um balanço entre os valores recebidos (Fundurb) e os valores gerados (OODC). ${ }^{5}$ Os resultados se apresentam na Figura 8 junto com uma representação da distribuição da renda no município para contextualizar a leitura. 
Tabela 1 - Discriminação dos investimentos do Fundurb no período 2013-2018 ${ }^{6}$

\begin{tabular}{l|c|c}
\hline Investimento & Valor (US\$ milhões) & \% do total \\
\hline Administrativo & 5,05 & $1,17 \%$ \\
\hline Trabalho social & 10,17 & $2,36 \%$ \\
\hline Educação & 14,53 & $3,37 \%$ \\
\hline Compensação ambiental & 0,06 & $0,01 \%$ \\
\hline Desapropriações & 44,37 & $10,30 \%$ \\
\hline Habitação & 110,00 & $25,54 \%$ \\
\hline Infraestrutura & 39,46 & $9,16 \%$ \\
\hline Infraestrutura sanitária & 72,11 & $16,74 \%$ \\
\hline Lazer & 36,55 & $8,48 \%$ \\
\hline Transporte & 29,81 & $6,92 \%$ \\
\hline Carro particular & 25,98 & $0,60 \%$ \\
\hline Ciclovia & 4,06 & $0,94 \%$ \\
\hline Ônibus & 23,03 & $5,35 \%$ \\
\hline Pedestre & 38,93 & $9,04 \%$ \\
\hline Total & 430,75 & $100,0 \%$ \\
\hline
\end{tabular}

As áreas de ponderação em tons de azul são aquelas em que houve um saldo de maior investimento do que de geração de recursos enquanto as áreas em em tons de vermelho são as que geraram mais recursos do que receberam em investimentos. O mapa da Figura 8 (tons de azul x tons de vermelho) oferece um resultado alentador. As decisões públicas de investimento dos recursos advindos da Outorga Onerosa de Direito de Construir (OODC) no município têm sido alocadas principalmente nas áreas não geradoras. As áreas mais fortes em tons de azul coincidem com regiões pobres da cidade (em termos de renda; mapa à direita). Evidentemente, algumas áreas precisam de maior prioridade no investimento público: o extremo norte (Tremembé-Jaçanã), Brasilândia, Cachoerinha, o extremo leste (Itaim Paulista, Guaianases, Cidade Tiradentes), e o extremo sul (M'Boi Mirim, Capela do Socorro, Parelheiros). O ponto central da cidade (Sé), região dotada de enorme infraestrutura de suporte, pode ter justificado recebimentos de recursos do Fundurb para promoção de habitação de interesse social.

É importante frisar que o resultado alentador tem base num dos princípios da OODC. Os recursos têm destinação específica em objetivos de natureza redistributiva, como é a moradia social, o transporte coletivo e outros elementos 


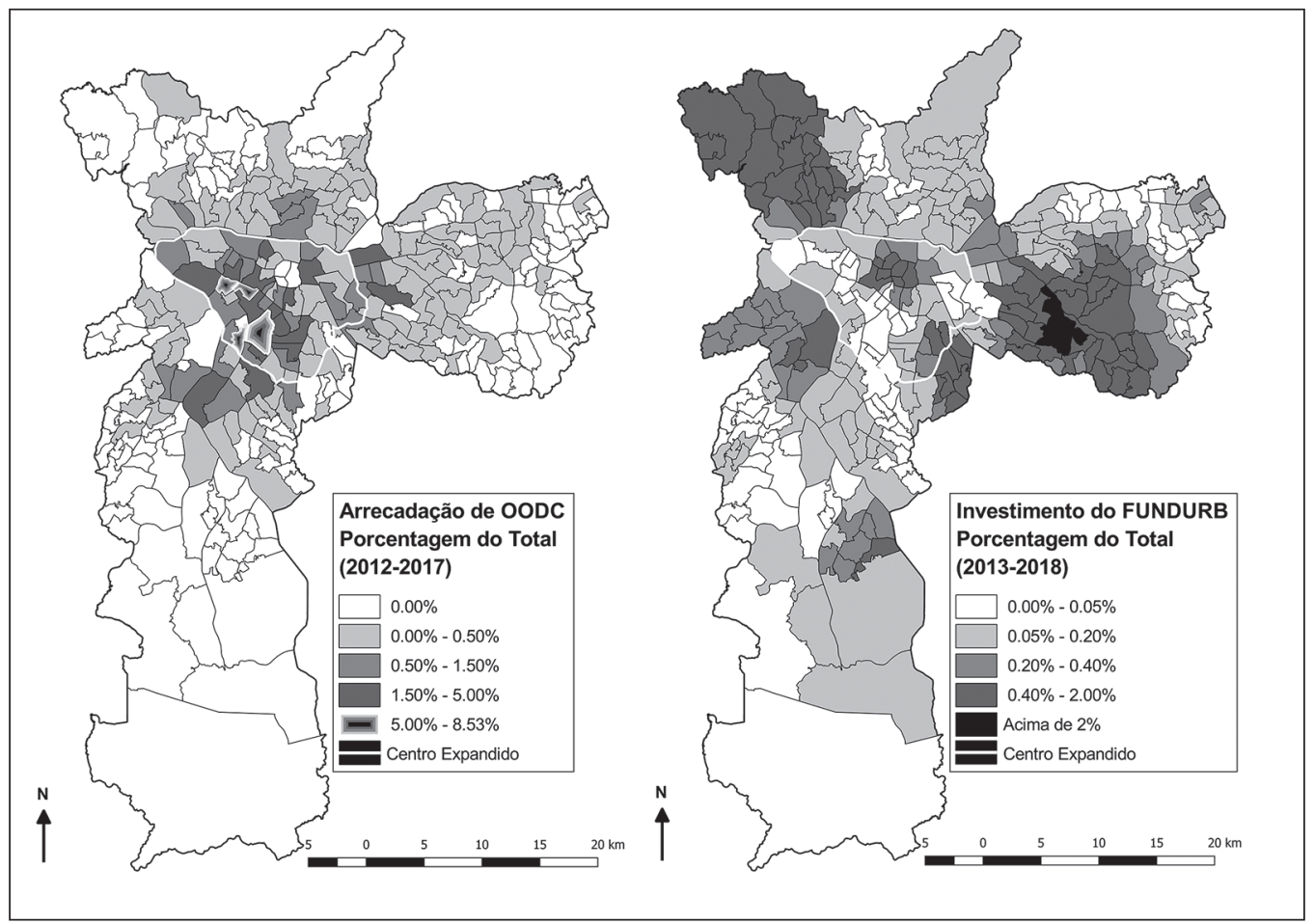

Fonte: DEUSO/SMUL/PMSP.

Figura 7 - Comparação das áreas de ponderação geradoras de arrecadação de OODC (2012-2017) e receptoras de investimentos pelo Fundurb (2013-2018).

relativos à infraestrutra de suporte da cidade. Essa é uma vantagem da OODC quando comparada a outros instrumentos de financiamento urbano que tendem a concentrar as disparidades espaciais ao limitar o uso dos recursos, por exemplo, ao perímetro próximo ou inclusive imediato da área geradora. Porém, o debate precisa ser colocado de forma mais ampla, pois, se o recurso se limitasse ao perímetro próximo da área geradora, mas "carimbado" em sua destinação para fins redistributivos, por exemplo, para moradia social, o impacto na distribuição da renda seria muito superior do que um recurso "carimbado" que se concentra só nas áreas pobres. Assim, para que os instrumentos de financiamento urbano atendam o objetivo de reduzir as disparidades criadas pelos diferenciais do preço da terra, serviços e infraestruturas, precisamos observar critérios territoriais e de destinação do investimento. Caso contrário, podemos acentuar as diferencias já marcadas entre as áreas das oportunidades e as áreas de vulnerabilidade de nossas cidades.

As ações públicas continuadas nas mesmas regiões da cidade são responsáveis pela concentração das oportunidades. A combinação entre arrecadação e investimento de modo redistributivo neste caso (OODC e Fundurb) rompe essa má "tradição" da nossa cidade e oferece oportunidade de reverter o ciclo vicioso de investimentos, direcionando-os às regiões mais carentes e de maior vulnerabilidade social e de saúde. 


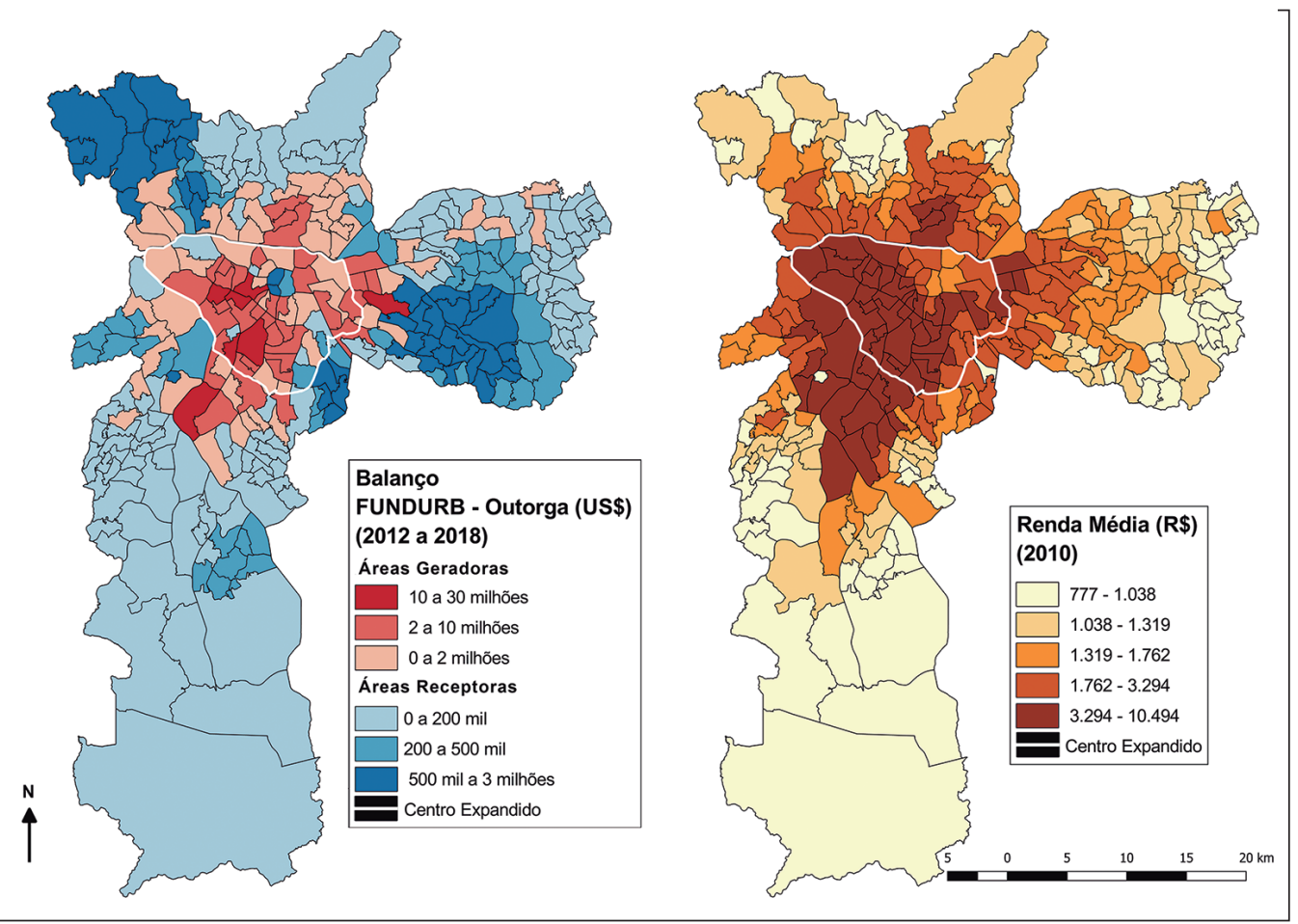

Fonte: SMUL/PMSP; IBGE (2010).

Figura 8 - Balanço entre geração de recursos da OODC e o investimento por área de ponderação (2012-2018) e distribuição espacial da renda (2010.

\section{Considerações finais}

As evidências mostram claramente o alinhamento das desigualdades sociais, o uso do território e as condições de saúde no município de São Paulo. Territórios com maiores carências nas condições de moradia e infraestrutura de suporte são aqueles onde vivem as populações com maiores vulnerabilidades social e em saúde. Essencialmente, tem-se: (i) as populações mais carentes e pobres moram nas regiões mais periféricas, distantes e com piores condições de infraestrutura e serviços urbanos e de mobilidade urbana. São os territórios menos valorizados e, muitas vezes, informais; (ii) essas populações são as que apresentam piores condições de saúde.

Por outro lado, as análises mostram que o principal instrumento de financiamento urbano para promoção de inclusão socioespacial que tem sido aplicado no município, a OODC, tem o seu funcionamento adequado no município a partir das duas variáveis investigadas: onde se arrecadam recursos, nas regiões com melhores condições de infraestrutura de suporte e, portanto, mais valorizadas; onde se aplicam recursos, ou seja, a destinação dos recursos de financiamento ocorre nos territórios de maior carência de habitação e infraestrutura de suporte, menos valorizados e com presença de maiores vulnerabilidades social e em saúde. 
O instrumento da OODC, portanto, possui grande potencial para atuar na mitigação das condições de vulnerabilidades social e em saúde no território.

Porém, as análises apontam a demanda por pesquisa qualitativa cuidadosa referente aos itens dos investimentos realizados nas regiões corretas. Os itens carecem de informações públicas precisas em suas descrições. Há que buscá-las e submetê-las à análise qualitativa. Esta será a próxima etapa deste trabalho.

Ou seja, a OODC está cumprindo seu objetivo ao destinar investimentos públicos decorrentes de política fundiária nos lugares corretos e os valores foram mensurados. Mas falta discriminar e qualificar tais investimentos. Há uma carência de parâmetros objetivos e rigorosos na definição dos itens financiados, até para que esses ganhem maior consistência em termos de continuidade de políticas públicas, além de corretas definições e, consequentemente não sujeição à escolhas políticas inconsistentes e questionáveis.

$\mathrm{O}$ instrumento pode e deve ser otimizado para melhor atuar nessas duas demandas - onde e o quê - de modo mais robusto, com maior foco e eficácia.

$\mathrm{O}$ instrumento deve ser potencializado e não desidratado conforme proposta de revisão do marco regulatório urbano apresentada pela atual gestão, ao propor desconto de $30 \%$ no valor da OODC gerando significativa redução de recursos ao Fundurb (Leite et al., 2018).

O instrumento pode ser incrementado mediante a adoção de indicadores objetivos derivados de evidências empíricas, baseados em pesquisa científica, como mostrado neste artigo.

Promover-se-ia também maior transparência pública na aplicação dos recursos, com a publicação periódica dos indicadores e mapeamento socioespacial das desigualdades sociais e em saúde para acompanhamento da sociedade e das comunidades que receberão os recursos. Esse é um ponto-chave para evitar as alterações de destinação. O mapeamento contínuo dos investimentos poderia, por exemplo, ser colocado como mais um indicador na página de monitoramento territorial da prefeitura de São Paulo, o Gestão Urbana SP. ${ }^{7}$

$\mathrm{O}$ aperfeiçoamento do instrumento, com base em indicadores espacializados de vulnerabilidade social e em saúde urbana, o coloca como uma potente ferramenta de política pública multisetorial integrada e territorializada. Pode-se, por exemplo, usá-lo como elemento articulador de diversos planos setoriais, como o Plano Municipal de Habitação (PMH), o Plano Municipal de Mobilidade Urbana) (PlanMob), de equipamentos públicos, de educação e de saúde pública.

O lado positivo da importância do lugar é que ele pode ser atuante na saúde das populações de formas diversas. Nessa escala, são a proximidade, a oferta, a possibilidade de acesso que têm o potencial de alterar o comportamento das pessoas, inclusive pela interação social e pelas redes que se estabelecem. Reduzir a segregação pode ter efeito positivo no bem-estar das pessoas. Mas como diminuir a segregação? Torres et al. (2003) ponderam que se o Estado gera 
segregação por ações governamentais, também é ele quem teria condições de promover a integração. Os mecanismos seriam por meio de ações que os autores chamaram de políticas governamentais relativas ao espaço construído e políticas sociais "espacialmente organizadas". Entre as primeiras estariam as ações de regulamentação urbana e investimentos em infraestrutura nos bairros mais pobres. No segundo grupo estariam as políticas sociais tradicionais nas áreas de educação, saúde, assistência social, esportes, cultura e lazer pela transformação do espaço, acesso e inserção dos diferentes grupos sociais.

Agradecimento - Claudia Acosta agradece o apoio da Coordenação de Aperfeiçoamento de Pessoal de Nível Superior - Brasil (Capes) - Código de financiamento 001 - para a realização deste trabalho. Agradece também o apoio técnico de Vitor Estrada Oliveira do CEPESP/FGV.

\section{Notas}

1 Óbitos entre crianças de 28 a 364 dias de vida completos, menos associados a problemas decorrentes do atendimento durante o parto.

2 Detalhes metodológicos dessa análise podem ser encontrados em Barrozo (2018)

3 Detalhes da metodologia da análise de regressão espacial são encontrados em Barrozo (2018)

$4 \mathrm{O}$ raio dos investimentos não necessária ou exclusivamente corresponde á área de ponderação (unidade territorial adotada no estudo) em que está localizado, em especial aqueles localizados nos limites divisórios.

5 Para evitar distorções no resultado, cada grupo foi dividido em intervalos em função do comportamento dos dados e identificando os registros de OODC e Fundurb que representavam uma distancia muito grande com o grupo de dados. Ambas informações foram apresentadas em percentual para facilitar a leitura.

6 Os dados do Fundurb foram acessados no site <https://www.prefeitura.sp.gov. br/cidade/secretarias/urbanismo/participacao_social/fundos/fundurb/index. php?p=177712>. Muitos dados não estão disponíveis. Os dados de 2018 não apresentam os valores corretamente, apenas para alguns investimentos, por isso, só foram considerados aqueles com informação correta. Para os polígonos e linhas localizados em mais de uma área de ponderação, foi distribuído o recurso utilizado em proporção ao tamanho dentro de cada área. Os dados da OODC foram levantados a partir do contraste entre a base do DEUSO e o sistema GeoSampa (http:/ /geosampa.prefeitura. sp.gov.br/PaginasPublicas/_SBC.aspx). Dadas as importantes diferenças entre ambas fontes, deu-se prelação aos dados cotejados do DEUSO. Por fim, foi utilizado o Censo de 2010 por setor censitário (IBGE, 2010). A conversão de dados a dólar se realizou de acordo com o ano em que foi definido cada valor.

7 Disponível em: <https://gestaourbana.prefeitura.sp.gov.br>. 


\section{Referências}

BARROZO, L. Desigualdades na mortalidade infantil no Município de São Paulo: em busca do melhor indicador. Confins, n.37, 24 set. 2018. Disponível em: <http://journals.openedition.org/confins/15010>.

BARROZO, L. et al. Changing spatial perception: dasymetric mapping to improve analysis of health outcomes in a megacity. Journal of Maps, v.5647, n.22, p.1-6, out. 2015. Disponível em: <http://www.tandfonline.com/doi/full/10.1080/17445647. 2015.1101403>

BURGARELLI, R. et al. 1\% dos donos de imóveis concentra 45\% do valor imobiliário de São Paulo. Estadão Dados, 13.8.2016. Disponível em: <https://www.estadao.com. $\mathrm{br} /$ noticias/geral,l-dos-donos-de-imoveis-concentra-45-do-valor-imobiliario-de-sao-paulo,10000069287>.

CALDEIRA, T. Building up walls: the new pattern of spatial segregation in São Paulo. International Social Sciences Journal, v 48, n.147, 1996.

CARLOS, A. São Paulo: dinâmica urbana e metropolização. Revista Território, Rio de Janeiro, ano VII, p.77-89, set./out. 2003.

CASTELLS, M. La questión urbana. Ciudad de Mexico: Siglo Veintiuno Editores, 1978.

DEATON, A. Health, Inequality, and Economic Development. Journal of Economic Literature, v.41, n.1, p.113-58, mar. 2003. Disponível em: <http://pubs.aeaweb.org/ doi/abs/10.1257/002205103321544710>

EGUINO, H.; LEITE, C. ¿Como mejorar los ingresos municipales y prepararse para acceder a financiamiento?: la importancia de una buena gestión fiscal. In: Red de Ciudades (ed), Reunión Anual de Alcades y Seminario: "Ciudades Incluyentes: Aprendiendo de Medellin”. Documento Técnico. Medellín: Banco Interamericano de Desenvolvimento (BID), 2018, p.161-74.

FAJERSZTAJN, L.; VERAS, M.; SALDIVA, P. Como as cidades podem favorecer ou dificultar a promoção da saúde de seus moradores? Estudos Avançados, São Paulo, v.30, n.86, 2016. Disponível em: <http://dx.doi.org/10.1590/S010340142016.00100002>.

FLOWERDEW, R.; MANLEY, D. J.; SABEL, C. E. Neighbourhood effects on health: Does it matter where you draw the boundaries? Social Science \& Medicine, v. 66, n. 6, p. 1241-1255, mar. 2008. Disponível em: <http://linkinghub.elsevier.com/retrieve/ pii/S0277953607006272>.

FURTADO, F; ACOSTA, C. Recuperación de plusvalias urbanas en Brasil, Colombia y otros paises de América Latina: legislación, instrumentos e implementación. Lincoln Institute of Land Policy. 2013. Disponivel em: <https://www.lincolninst.edu/sites/ default/files/pubfiles/2230_1564_Furtado_WP13FF1SP.pdf>.

HUYNH, M. et al. Spatial social polarization and birth outcomes: preterm birth and infant mortality - New York City, 2010-14. Scandinavian Journal of Public Health, p.1-10, 6 abr. 2017. Disponível em:<http://journals.sagepub.com/ doi/10.1177/1403494817701566>.

IBGE (INSTITUTO BRASILEIRO DE GEOGRAFIA E ESTATÍSTICA). Censo Demográfico 2010: notas metodológicas. [s.l: s.n.]. 
KRIEGER, N. et al. Using the Index of Concentration at the Extremes at multiple geographical levels to monitor health inequities in an era of growing spatial social polarization: Massachusetts, USA (2010-14). International Journal of Epidemiology, v.47, n.3, p.788-819, l jun. 2018. Disponível em: <https://academic.oup.com/ije/article $/ 47 / 3 / 788 / 4924394>$.

LEITE, C.; ACOSTA, C.; HADDAD, F.; SUTTI, W. Urbanismo social em São Paulo. Política pública fundiária e instrumentos indutores desenvolvidos no período 20132016 (gestão Haddad). Revista Arquitextos, v.219, n.6, 2018. Disponível em: <http:// www.vitruvius.com.br/revistas/read/arquitextos/19.219/7103>.

LEITE, C. et al. Social Urbanism in Latin America. Cases and Instruments of Planning, Land Policy and Financing the City Transformation with Social Inclusion. Basel: Springer Nature, 2019. DOI 10.1007/978-3-030-16012-8.

LEITE, C.; SALDIVA, P.; BRESSER-PEREIRA, L. Proposta de revisão do zoneamento na capital paulista feita pela atual gestão representa retrocesso nas políticas públicas urbanas. Nexo Jornal, 26 maio 2018. Disponível em: <https://www.nexojornal.com.br/ ensaio/2018/O-Plano-Diretor-de-S\%C3\%A3o-Paulo-est\%C3\%Al-amea\%C3\%A7ado>

LENCIONI, S. Concentração e centralização das atividades urbanas: uma perspectiva multiescalar. Reflexões a partir do caso de São Paulo. Revista de Geografía Norte Grande, n.39, maio 2008. Disponível em: <http://www.scielo.cl/scielo.php?script=sci_ arttext\&pid=S0718-34022008000100002\&lng=en\&nrm=iso\&tlng=en > .

MACKENBACH,J.Persistence of socialinequalitiesin modernwelfare states: Explanation of a paradox. Scandinavian Journal of Public Health, v.45, n.2, p.113-20, 21 mar. 2017. Disponível em: <http://journals.sagepub.com/doi/10.1177/1403494816683878>.

MARMOT, M. The Health Gap: The Challenge of an Unequal World: the argument. International Journal of Epidemiology, v.46, n.4, p.1312-18, 1 ago. 2017. Disponível em: <http://academic.oup.com/ije/article/46/4/1312/4102087/The-Health-Gap-The-Challenge-of-an-Unequal-World>

MARQUES, E. Urban Poverty, Segregation and Social Networks in São Paulo and Salvador, Brazil. International Journal of Urban and Regional Research, v.39, n.6, p.106783, 2015. Disponível em: <http://doi.wiley.com/10.1111/1468-2427.12300>.

MASSEY, D. The age of extremes: concentrated affluence and poverty in the twenty-first century. Demography, v.33, p.395-412, 1996.

NOBRE, E. Recuperação da valorização imobiliária para financiamento da transformação urbana. In: BALBIM; KRAUSE. Eixos de estruturação da transformação urbana: inovação e avaliação em São Paulo. Brasília: IPEA, 2016. p.161-215.

ONU (Organização das Nações Unidas). Transformando Nosso Mundo: A Agenda 2030 para o Desenvolvimento Sustentável. Objetivos de Desenvolvimento Sustentável. ONU, 2015.

PHELAN, J.; LINK, B.; TEHRANIFAR, P. Social Conditions as Fundamental Causes of Health Inequalities: Theory, Evidence, and Policy Implications. Journal of Health and Social Behavior, v.51, n.1_suppl, p.S28-S40, 8 mar. 2010. Disponível em: <http:// journals.sagepub.com/doi/10.1177/0022146510383498>.

RNSP (REDE NOSSA SÃO PAULO). São Paulo das desigualdades: as muitas cidades dentro de uma só. Disponível em: <https://32xsp.org.br/especial/sao-paulo-das-desigualdades>. Acesso em: 25 fev. 2019. 
ROEDER, A. Zip code better predictor of health than genetic code. 2014. Disponível em: <https://www.hsph.harvard.edu/news/features/zip-code-better-predictor-of-health-than-genetic-code/>. Acesso em: 14 out. 2017.

SABATINI, F. The Social Spatial Segregation in the Cities of Latin America. [s.l: s.n.].

SALDIVA, P. Vida Urbana e Saúde. Os Desafios dos Habitantes das Metrópoles. São Paulo: Contexto, 2018.

SEADE (Fundação Sistema Estadual de Análise de Dados). Censo Amostral de Favelase Loteamentos Irregulares na Cidade de São Paulo. São Paulo: Sehab/Seade, 2008.

SMDU (Secretaria Municipal de Desenvolvimento Urbano). Território CEU: rede de equipamentos e espaços públicos. São Paulo: SMDU, Prefeitura da Cidade de São Paulo, 2016.

SMH (Secretaria Municipal de Habitação da Prefeitura da Cidade de São Paulo). Plano Municipal de Habitação - Caderno para Discussão Pública. São Paulo, SEHAB/PMSP, 2016

SMOLKA, M.; AMBORSKI, D. Apropiación de valor para el desarrollo urbano: una comparación Inter-Americana. Lincoln Institute of Land Policy. 2000. Disponivel em: $<$ https://www.lincolninst.edu/publications/working-papers/recuperacion-plusvalias-para-el-desarrollo-urbano $>$.

TORRES, H. et al. Pobreza e espaço: padrões de segregação em São Paulo. Estudos Avançados, São Paulo, v.17, n.47, p.97-128, abr. 2003. Disponível em: <http://www. scielo.br/scielo.php?script=sci_arttext\&pid=S0103-40142003000100006\&lng=pt\&tl $\mathrm{ng}=\mathrm{pt}>$.

VILLAÇA, F. São Paulo: urban segregation and inequality. Estudos Avançados, São Paulo, v.25, n.71, p.37-58, 2011.

UN Habitat. KUALA LUMPUR DECLARATION ON CITIES 2030. KualaLampur: UN Habitat, 2018.

WATSON, T. Inequality and the measurement of residential segregation by income in American neighborhoods. Review of Income and Wealth, v.55, n.3, p.820-44, 2009.

WEISS, D.; EIKEMO, T. Technological innovations and the rise of social inequalities in health. Scandinavian Journal of Public Health, v.45, n.7, p.714-19, 22 nov. 2017. Disponível em: <http://journals.sagepub.com/doi/10.1177/1403494817711371>.

RESUMO - Neste artigo analisamos as condições de vulnerabilidades social e em saúde e a segregação residencial no município de São Paulo e o potencial uso de medidas científicas para instrumentos de financiamento urbano enquanto política pública promotora de inclusão socioterritorial. A pesquisa investiga quatro problemas complementares, com enfoques inter e multi-disciplinares, ao analisar: (i) as evidências que vinculam as condições de saúde e vulnerabilidade socioespacial no território; (ii) os principais indicadores das condições de segregação residencial e desigualdades socioespaciais; (iii) os principais instrumentos de financiamento urbano existentes na política fundiária com maior potencial de utilização no financiamento da mitigação das desigualdades sociais e em 
saúde no uso do território. Ao apontar a carência da utilização de evidências empíricas, indicadores baseados em pesquisa científica, na aplicação dos instrumentos de financiamento urbano identificados como promotores da mitigação das desigualdades, o artigo discute o aperfeiçoamento do instrumento, com base em indicadores espacializados de vulnerabilidade social e em saúde urbana, colocando-o como potente ferramenta de política pública multisetorial integrada e territorializada.

PALAVRAS-CHAVE: Financiamento urbano, Desigualdade social, Saúde urbana, Políticas públicas urbanas, Política fundiária.

ABSTRACT - In this article we analyze the conditions of social and health vulnerability, residential segregation in the city of São Paulo and the potential use of scientific measures for instrumentas of urban financing as a public policy promoting social and territorial inclusion. The research investigates four complementary problems, with inter- and multi-disciplinary approaches, when analyzing: (i) the evidence that links health conditions and socio-spatial vulnerability in the territory; (ii) the main indicators of residential segregation and socio-spatial inequalities; (iii) the main land-based tools and funding instruments with the greatest potential to finance the mitigation of social and health inequalities in the use of territory. By pointing out the lack of use of empirical evidence, of indicators based on scientific research, and of the application of urban financing instruments identified as promoters of inequality mitigation, this article discusses how to improve the instrument, based on spatialized indicators of social vulnerability and urban health, placing it as a powerful tool for integrated and territorialized multisectoral public policy.

KErWORDS: Urban financing, Social inequality, Urban health, Urban public policies, Land policy.

Carlos Leite é urbanista, PhD, professor da Faculdade de Arquitetura e Urbanismo da Universidade Presbiteriana Mackenzie, professor convidado no PPG-CIS-Uninove e pesquisador convidado do IEA-USP (Programa Cidades Globais e Grupo de Estudos Espaço Urbano e Saúde). @ - carlos.souza@mackenzie.br /

https://orcid.org/0000-0003-3569-9141

Claudia Acosta é mestre, advogada especialista em Direito Urbano e Política Fundiária. É professora do Lincoln Institute of Land Police (Cambridge, MA), doutoranda na Fundação Getulio Vargas (FGV), pesquisadora do Centro de Política e Economia do Setor Público (Cepesp/FGV) e consultora do BID e UN-Habitat.

$@$ - claudiamarcelaacosta@gmail.com / https://orcid.org/0000-0001-9599-0411

Tereza Herling é arquiteta urbanista, professora doutora da Faculdade de Arquitetura e Urbanismo da Universidade Presbiteriana Mackenzie e consultora sênior de políticas públicas e desenvolvimento urbano junto ao Banco Mundial e Cities Allience.

@ - terezaherling@gmail.com / https://orcid.org/0000-0003-4828-2855

Ligia Vizen Barrozo é geógrafa, professora associada do Departamento de Geografia da Faculdade de Filosofia, Letras e Ciências Humanas da Universidade de São Paulo e coordenadora do Grupo de Estudos "Espaço Urbano e Saúde” do Instituto de Estudos Avançados da USP. @- lija@usp.brlija@usp.br / https://orcid.org/0000-0001-7322-6789 
Paulo Hilário Nascimento Saldiva é médico patologista, professor titular do Departamento de Patologia da Faculdade de Medicina da Universidade de São Paulo e diretor do Instituto de Estudos Avançados da Universidade de São Paulo (2016-2020).

@ - pepino@usp.br / https://orcid.org/0000-0003-2005-8253

I, III Faculdade de Arquitetura e Urbanismo, Universidade Presbiteriana Mackenzie, São Paulo, Brasil.

II Lincoln Institute of Land Police, Cambridge, MA, EUA.

IV Faculdade de Filosofia, Letras e Ciências Humanas, Universidade de São Paulo, São Paulo, São Paulo, Brasil.

${ }^{v}$ Faculdade de Medicina, Universidade de São Paulo, São Paulo. Brasil.

Recebido em 13.6.2019 e aceito em 13.8.2019. 